Estudios Constitucionales, Año 8, No 2, 2010, pp. 15 - 30.

ISSN 0718-0195

Centro de Estudios Constitucionales de Chile Universidad de Talca

"El (re) surgimiento de un concepto:

la búsqueda del verdadero sentido de la democracia en la sociedad contemporánea"

Clovis Gorczevski - Caroline Muller Bitencourt

\title{
EL (RE) SURGIMIENTO DE UN CONCEPTO: LA BÚSQUEDA DEL VERDADERO SENTIDO DE LA DEMOCRACIA EN LA SOCIEDAD CONTEMPORÁNEA
}

\author{
Clovis Gorczevski ${ }^{1}$ \\ Profesor de la Universidad de Santa Cruz do Sul - UNISC \\ clovis.g@terra.com.br
}

Caroline Muller BitencourT ${ }^{2}$

Profesora de la Universidad de Santa Cruz do Sul - UNISC

\begin{abstract}
"Derechos del hombre, democracia y paz son tres momentos necesarios del mismo movimiento histórico: sin derechos del hombre reconocidos y protegidos no hay democracia; sin democracia no existen minimas condiciones para la solución pacifica de conflictos. En otras palabras, la democracia es la sociedad de los ciudadanos, y los súbditos se hacen ciudadanos cuando se les reconoce algunos derechos fundamentales; habrá paz estable, una paz que no tenga guerra como alternativa, solamente cuando existan ciudadanos no más sólo de este o de aquel Estado, sino ciudadanos del mundo". Norberto Bobbio
\end{abstract}

RESUMEN: El constitucionalismo democrático del siglo XXI, anclado en el binomio dignidad humanal solidaridad social, acaba chocándose con una cultura jurídica extremadamente positivista proveniente de una legislación históricamente fundada en normas de derecho privado. Estos derechos fundamentales, mientras principios supremos de una comunidad y ahora provistas de fuerza jurídica y eficacia inmediata, puesto su positivación, dependen también, para su efectividad, de acciones conjuntas, pues como metas y objetivos electos por una comunidad presuponen participación politica y jurídica, tanto en su respeto, como en su interpretación y aplicabilidad, lo que permite una apertura constitucional a sus ciudadanos, concretizando asi la propia Constitución a través de la democratización del sistema de derechos fundamentales. En esta estela, el "nuevo" concepto de democracia se vuelve indisociable de la idea de concretización de los derechos fundamentales, motivo por el que los tiempos "post-modernos" exigen un nuevo modelo de ciudadano: un sujeto activo y transformador de la sociedad en la que se inserta.

\footnotetext{
${ }^{1}$ Abogado. Doctor en derecho, profesor de la Universidad de Santa Cruz do Sul - UNISC. Artículo recibido el 15 de octubre de 2009 y aprobado el 16 de junio de 2010.

${ }^{2}$ Abogada, Maestra en Derecho. Profesora de la Universidad de Santa Cruz do Sul - UNISC.
} 
ABSTRACT: The XXI century's democratic constitutionalism, based on binomial human dignity/social solidarity, has just collided with an extremely positivist legal culture arising from a legislation based on historical standards of private law. These fundamental rights, as supreme principles of a community, and now as standards provided with legal force and immediate efficiency, given their positivation, also depend, for their effectiveness, in joint actions, because goals and objectives elected by a community assume political and legal participation, both in its respect and its interpretation and application, which allows a constitutional opening for its citizens, thereby giving effect to the Constitution through the democratization of the system of fundamental rights. Therefore, the "new" concept of democracy becomes inseparable from the idea of realizing the fundamental rights, reason why the "post-modern" times require a new type of citizen: an active and transforming person of the society in which he is part of.

PALABRAS ClaVE: Constitucionalismo democrático. Derechos fundamentales. Ciudadanía activa.

KEY WORDS: Democratic constitutionalism. Fundamental rights. Active citizenship.

\section{CONSIDERACIONES INICIALES}

La popularización de un concepto siempre presenta dos sentidos: si por un lado hacerlo conocido podrá generar mayor amplitud y mayor número de personas buscando su concretización, de igual modo podrá incurrir en la banalidad, lo que podría provocar la usurpación del real valor y sentido que este concepto abarca.

Así, se parte de la cuestión de que si la utilización del término, palabra o concepto de democracia, hoy tan banalizado en el discurso retórico y popular, abarca la verdadera gama de sentidos y el verdadero "peso" de la democracia en la sociedad contemporánea. Porque no se habla de un (re)surgimiento del tradicional concepto, mucho más amplio, mucho más complejo y mucho más comprometido con los preceptos y valores incorporados con las Constituciones modernas, más propiamente con la Constitución Ciudadana de 1988, opción del Constituyente Originario tras largos años de represión de derechos, donde una vez más en la historia, tantas voces se callaron ante el poder de pocos.

Sus precursores, sea en Grecia, en Atenas con Aristóteles en una referencia más remota, primitiva o en la Europa de la Revolución Francesa con Rousseau en una versión moderna, vieron en la democracia la forma a través de la que el pueblo podría participar de la vida política, de las decisiones que decidieron sus vidas, sus propios destinos y el destino de su gente, de su pueblo.

Sería incurrir en un error no sólo conceptual, sino también histórico si continuáramos pensando en la democracia como una forma de gobierno ejercida ante la soberanía popular, el sufragio universal, en el que prevalece la voz de la mayoría. Innegable la importancia histórica en sentido de su ejercicio, las luchas por el derecho de participación en el poder político, pero la democracia en el constitucionalismo contemporáneo asume una gama de obligaciones solidarias y correlacionadas entre sí. 
$\mathrm{Al}$ concepto de forma de gobierno, con la participación popular a través del sufragio universal, debemos agregar el sentido de compromiso ciudadano con las cuestiones asumidas, como una especie de onus democrático de una sociedad que condiciona la concretización de sus objetivos y preceptos al ejercicio de perfeccionamiento de la democracia. Todos somos co-responsables de la realización de una sociedad justa y solidaria, que busca erradicar la pobreza y hacer justicia social a través del respeto a la dignidad de la persona humana. En esta tarea, estamos imbuidos de una acción activa a través del ejercicio de una ciudadanía plena, donde la democracia y la voluntad popular no más serán soberanas, sino condicionadas y subordinadas a la concretización de los derechos fundamentales.

\section{BREVE EXPOSICIÓN DEL PRINCIPIO DEMOCRÁTICO}

Los ideales democráticos surgieron en el siglo XVIII, buscando eliminar algunas prácticas absolutistas y crear no solamente un Estado subordinado a la ley, sino también a la voluntad popular. De ahí el concepto de democracia de gobierno del pueblo, ejercido por el pueblo y para el pueblo.

Democracia es un concepto histórico. No siendo por si un valor-fin, sino medio e instrumento de realización de valores esenciales de convivencia humana, que se traducen básicamente en los derechos fundamentales del hombre, se comprende que la historicidad de éstos la involucra a la misma medida, enriqueciéndole el contenido a cada etapa del involucrar social, mantenido siempre el principio básico de que ella devela un régimen politico en el que el poder del pueblo reposa en la voluntad del pueblo. Bajo ese aspecto, la democracia no es un mero concepto político abstracto y estático, sino es un proceso de afirmación que el pueblo va conquistando a lo largo de la historia ${ }^{3}$.

En este punto es importante establecer que el principio democrático abarca dos grandes postulados. El primero, el de la democracia representativa, apareciendo bajo forma de los órganos representativos, pluralismo partidario, elecciones periódicas, separación de poderes. Y también el de la democracia participativa, que comprende la estructuración de procesos, buscando dar a sus ciudadanos la posibilidad de participar activamente en los procesos decisivos, fiscalizar y ejercer el control en la divergencia de opiniones, o sea, cumplir efectivamente su papel de ciudadano en un Estado democrático ${ }^{4}$.

El principio democrático, a su vez, abarca conceptos que le dan esencia, pues el sumatorio de éstos refleja un Estado democrático. Hay que referirse en especial

${ }^{3}$ Silva (2000), p. 129.

${ }^{4}$ Canotilho (2003), p. 282. 
a la soberanía popular, que tras la teoría del poder constituyente enseña que el pueblo es la única fuente del poder, pues todo poder deberá emanar del pueblo; y las formas de participación directa o indirecta del pueblo en el poder para que éste sea la efectiva expresión de la voluntad popular, legitimando así la participación del pueblo en la vida política del Estado.

En esta estela, presenta diversas funciones dentro del Estado que lo adopta. Una de ellas es su dinamismo, no se puede pretender una conceptuación estática, se busca acompañar el desarrollo de sus ciudadanos ofreciendo formas de igualdad política, económica y social, propiciando así mejor calidad de vida. También es un principio informador de la sociedad, porque exige que ésta se organice y se encuadre según las voluntades políticas de sus ciudadanos. Eso desencadena un proceso llamado democratización. Es también un principio organizador del ejercicio y titularidad del poder, pues implanta una forma de organización de la comunidad a través del poder político legitimado a sus ciudadanos, tanto de elección, como de control y participación en la forma de Estado y de gobierno, la llamada autodeterminación y el autogobierno5.

Se vuelve complejo exponer todos los tipos y formas de democracia, pero es importante ubicar el modelo de democracia optado por el constituyente de 1988, la representativa. Se entiende por representación el enlace entre gobernantes y gobernados, en el que los gobernantes deberán actuar y trabajar a favor de la promoción del bienestar de sus gobernados. Esa representación se adquiere a través del mandato. Los principales sujetos de la representación política son los partidos políticos, pues son grupos políticamente organizados y debidamente instituidos para la disputa del poder.

Agregada al modelo representativo también está la participación directa del ciudadano por medio de los instrumentos: el plebiscito, que es una consulta popular sobre dicho asunto; el referéndum, forma de manifestación popular sobre una actitud gubernamental, debiendo aprobarla o rechazarla; y la iniciativa popular, que es presentación de un nuevo proyecto de ley de parte de una parcela de la población que deberá ser examinado y posteriormente puesto en votación y que podrá ocurrir en el ámbito provincial y municipal ${ }^{6}$.

Pero ese principio es la esencia del Estado que tiene como fundamento una sociedad justa, libre e igualitaria. El principio democrático mientras función y contribución social inviste al ciudadano del poder de elegir a quien lo representará y también del derecho de participar efectivamente en los procesos que determinan los rumbos de la nación. Esa participación activa y política hace los ciudadanos

${ }^{5}$ CANOtilho (2003), pp. 283-284.

${ }^{6}$ Bastos (2001), p. 281. 
iguales en ese Estado, siendo capaces de realizar toda la gama de derechos que la CRFB/1988 (Constitución de la República Federativa de Brasil) establece. Seguidamente se refiere que la democracia solamente se hace a través de la participación de sus ciudadanos, por eso es importante la exposición de lo que viene a ser el ciudadano en el escenario político brasileño.

\section{LA CIUDADANÍA EN EL EJERCICIO DE LA DEMOCRACIA BRASILEÑA}

La ciudadanía se eleva a uno de los fundamentos del Estado brasileño, pues la propia CRFB/1988 (Constitución de la República Federativa de Brasil) se titula como una Constitución ciudadana, tanto por la participación popular en el proceso de elaboración, como por el hecho de que está extremadamente vuelta a la realización de la ciudadanía que solamente se efectúa por la participación de los ciudadanos. Sin embargo, antes de entrar en el mérito de esta cuestión, cabe exponer la distinción propuesta por el legislador constituyente de 1988 en lo que se refiere a la ciudadanía y a la nacionalidad.

Primeramente, componen el pueblo brasileño los nacionales, brasileños natos y naturalizados y extranjeros residentes en el territorio nacional, que por algún motivo no adquirieron nacionalidad brasileña. No quiere decir que por el hecho de que poseen nacionalidad serán ciudadanos del Estado brasileño, los ciudadanos serán aquellos nacionales investidos de derechos políticos que participen activa o pasivamente en el escenario político:

El nacional no puede ser confundido con el ciudadano. La condición de nacional es presupuesto para la de ciudadano. En otras palabras, todo ciudadano es nacional, pero el revés no es verdadero: no todo el nacional es ciudadano. Lo que confiere esta última calificación es el goce de los derechos políticos. Ciudadano, pues, es todo el nacional en el goce de sus derechos civicos. Si por cualquier motivo no los ha adquirido aún (por ejemplo, a causa de la edad) o ya los haya poseido y un día vino a perderlos, el nacional no es ciudadano, en la acepción técnico-jurídica del término?.

De esa forma, comentar sobre ciudadanía es también reportarse a los derechos políticos, atribuidos al ciudadano en el Estado brasileño. Se distinguen los derechos políticos activos y pasivos y la manera de su adquisición:

I-Activos - los derechos politicos activos comienzan a los dieciséis años de forma facultativa y a los dieciocho años de forma obligatoria (de ahi que se habla que el voto es, además de un derecho, una función). Esa manifestación de los derechos políticos activos se da a

7 BASTOS (2001), p. 281. 
través de la capacidad de votar, participar del plebiscito y referendo, suscribir proyecto de ley de iniciativa popular y proponer acción popular.

Sin embargo, esos derechos no son automáticos. Se hace necesario el alistamiento electoral. Este, como ya se ha dicho, es obligatorio para mayores de dieciocho años y facultativo para los mayores de dieciséis y menores de dieciocho, para los analfabetos y para los mayores de setenta años. El alistamiento electoral está vedado a los menores de dieciséis años, a los extranjeros y a aquellos que estén cumpliendo servicio electoral obligatorio.

II - Pasivos - los derechos políticos pasivos consisten en la posibilidad de ser votado, a la cual se da el nombre de elegibilidad. Esta viene a ser, pues, la facultad que los brasileños poseen de presentarse como candidato al proveimiento de cargos públicos. En regla, todo aquel que se encuentra en la posesión de sus derechos politicos es elegible, desde que se aliste y que no sea analfabeto ${ }^{8}$.

El concepto de ciudadanía trata de una libertad política asociada al derecho de igualdad social, a la medida en la que la realización de la ciudadanía permite la democratización social. La ciudadanía es la realización democrática de una sociedad, exigiendo la organización social para instituir una política vuelta a la población, debiendo tener la participación de todos los individuos para así garantizar y compartir entre ellos condiciones dignas de vida y supervivencia, superando toda y cualquier forma de exclusión social?.

Por este prisma, el ejercicio de la ciudadanía tanto impone límites a los gobernantes, como propicia el acceso al espacio público, pues la ciudadanía es el eslabón de relación de la persona, titular de derechos, con el Estado, responsable por la garantía y promoción de ellos. Dichos derechos son los derechos reservados por la Carta Magna y característicos de la forma de Estado adoptada y de responsabilidad del Estado, tales como los derechos fundamentales. En este sentido resulta saludable la exposición de Lafer:

[...] la ciudadanía es el derecho de tener derechos, pues la igualdad en dignidad y derechos de los seres humanos no es un dato. Es una construcción del colectivo, que requiere el acceso público. Es este acceso al espacio público que permite la construcción de un mundo común a través del proceso de aserción de los humanos [...] De hecho, el proceso de aserción de los derechos humanos, mientras invención para el colectivo, exige un espacio público, al que sólo tiene acceso por medio de la ciudadanía ${ }^{10}$.

Por lo tanto, el principio de la ciudadanía es el responsable no solamente por la efectiva realización democrática, a la vez que consiste en el instrumento que la

\footnotetext{
${ }^{8}$ Bastos (2001), p. 282.

${ }^{9}$ CorrêA (2000), p. 217.

${ }^{10}$ CorrêA (2000), p. 220.
} 
viabiliza, como también es el principio formador del espacio público que deberá proporcionar la igualdad de condiciones entre sus ciudadanos, no sólo de subsistencia, sino también de garantía de derechos efectivamente cumplidos, sobre todo, de una vida digna.

\section{LA DEMOCRACIA COMO PRESUPUESTO A LA EXISTENCIA DE LOS DERECHOS FUNDAMENTALES, ¿¿O LA DEMOCRACIA COMO UN DERECHO FUNDAMENTAL?}

Los ideales democráticos y los derechos fundamentales tienen su conceptuación prácticamente indisociable, a la medida en que la inexistencia de alguno de los presupuestos de derechos fundamentales implica la inexistencia de un Estado democrático. La CRFB/1988 (Constitución de la República Federativa de Brasil) tiene como fundamento la soberanía nacional, ciudadanía, los valores sociales del trabajo y de la libre iniciativa y por fin el pluralismo político. Entonces se pregunta: ¡cómo alcanzar los ideales democráticos de la República Federativa de Brasil sin que los ciudadanos sean libres e iguales unos ante los otros y ante el propio Estado, para que ejerzan la soberanía nacional? ¿Sin que se propicie el acceso público a todos los ciudadanos? ¿Cómo hacer una sociedad justa sin que se respete primordialmente la dignidad de la persona humana? Ante dichas indagaciones se vislumbra la posibilidad de la efectiva realización del principio democrático cuando los derechos fundamentales posean la debida eficacia en el Estado Democrático de Derecho.

En ese sentido se hace necesaria la exposición de Canotilho para esclarecer la idea de derechos fundamentales como base esencial para la democracia:

Así como son un elemento constitutivo del Estado de derecho, los derechos fundamentales son un elemento básico para la realización del principio democrático. Más concretamente: los derechos fundamentales tienen una función democrática puesto el ejercicio democrático del poder: (1) significa la contribución de todos los ciudadanos para su ejercicio (principio-derecho de la igualdady de la participación politica); (2) implica participación libre asentada en importantes garantías para la libertad de ese ejercicio (el derecho de asociación, de formación de partidos; de libertad de expresión, son por ejemplo, derechos constitutivos del propio principio democrático); (3) co-envuelve la apertura del proceso politico en el sentido de creación de los derechos económicos y culturales. Hay que subrayar esta dinámica dialéctica entre derechos fundamentales y el principio democrático ${ }^{11}$.

Prima facie, los derechos fundamentales como master a las ideas de democracia se pueden considerar como garantía e instrumento del principio democrático de la

${ }^{11}$ Canotilho (2003), p. 283. 
autodeterminación de un pueblo donde cada individuo consciente de su papel de participación, así como reconociendo su derecho de igualdad en la construcción comunitaria y en el proceso político, se puede considerar como fundamento funcional de la orden democrática. La libertad de participación política que le posibilita al ciudadano participar en el proceso de decisión constituye un derecho, capaz de influir en los demás derechos fundamentales y en su eficacia en la sociedad, tanto que el ejercicio de los derechos políticos podrá considerarse como fundamento funcional de la orden democrática. La posibilidad de intervención política en el proceso de decisión y, consecuentemente, la intervención en el ejercicio de la soberanía se da a través de la libertad de participación política de los ciudadanos, elemento esencial de la democracia y derecho fundamental de los ciudadanos. La intervención resulta capaz de garantizar derechos de las minorías a la vez que se controlen los desvíos practicados por los representantes de los ciudadanos. En ese sentido, los derechos fundamentales sirven como instrumento moderador de abusos en la soberanía nacional ${ }^{12}$.

Sobre las funciones de los derechos fundamentales en el Estado democrático, es necesario precisar que:

A su vez, los derechos fundamentales, como derechos subjetivos de libertades, crean un espacio personal en contra del ejercicio de poder antidemocrático, y como derechos legitimadores de un dominio democrático, aseguran el ejercicio de la democracia ante la exigencia de garantías de organización y de procesos con transparencia democrática (principio mayoritario, publicidad critica, derecho electoral). Por fin, como derechos subjetivos a prestaciones sociales, económicas y culturales, los derechos fundamentales constituyen dimensiones impositivas al relleno intrinseco, a través del legislador democrático de esos derechos ${ }^{13}$.

La positivación de los derechos fundamentales en la CRFB/1988 (Constitución de la República Federativa de Brasil) sufre gran influencia de parte del espíritu democrático, porque la elaboración de los catálogos de derechos fundamentales de ese nuevo orden constitucional fue resultado de un amplio proceso de discusión involucrando la redemocratización del país, tras más de veinte años de régimen militar. Por obvio, la relevancia atribuida a los derechos fundamentales, más que en cualquier otra Constitución, estaría vuelta a asegurarles la democracia a sus ciudadanos, pues son frutos de las fuerzas sociales y políticas que emergieron en esta época.

${ }^{12}$ SARLET (2004), pp. 70-71.

${ }^{13}$ Canotilho (2003), p. 282. 
Más aún, se hace relevante agregar que el Estado Democrático de Derecho se sienta en dos pilares: la democracia y los derechos fundamentales. No hay democracia sin el respeto $y$ la realización de los derechos fundamentales-sociales y no hay derechos fundamentalessociales -en el sentido que se les atribuye por la tradición-sin democracia. Hay así, una copertenencia entre ambos. El contemporáneo constitucionalismo pensó en esa necesaria convivencia entre el régimen democrático y la realización de los derechos fundamentales previstos en las Constituciones ${ }^{14}$.

Otra cuestión de suma importancia suscitada "O problema fundamental em relação aos direitos do homem, hoje, não é tanto o de justificá-los, mas o de protegê-los. Trata-se de um problema não filosófico, mas político" ${ }^{15}$. Ante dicha afirmación se puede verificar que el efectivo cumplimiento de los derechos fundamentales depende básicamente del cumplimiento de la política adoptada por la forma de Estado, en este caso, la forma democrática, previendo no solamente la participación en el proceso decisorio, sino también siendo el instrumento para la realización de valores esenciales de la convivencia humana en sociedad.

Miranda destaca:

No basta con enumerar, definir, explicitar, asegurar sólo por si los derechos fundamentales; se hace necesario que la organización constitucional esté orientada hacia su garantía y su promoción. Asi como no basta con afirmar el principio democrático y buscar coincidencia entre la voluntad politica del Estado y la voluntad popular, en cualquier momento; es necesario establecer un cuadro institucional en el que esta voluntad se forme en libertad y en cada ciudadano tenga la seguridad de la previsibilidad del futur ${ }^{16}$.

Sin embargo, al pensarse en la máxima concretización de los derechos fundamentales, se puede, a la vez, cuestionar si habrá en este sentido una contradicción entre derechos fundamentales y democracia, ya que en nombre de los derechos fundamentales la propia esfera democrática a menudo estará limitada.

En este sentido, contesta Alexy a tal cuestión afirmando que hay tres modos de ver a la relación de los derechos fundamentales y democracia: un modo ingenuo, que cree que tanto la democracia como los derechos fundamentales se pueden tener ilimitadamente, pues ambos son buenos y entre buenos no hay conflicto; el modo de ver idealista, que dice que jamás los representantes políticos estarían interesados en herir los derechos fundamentales, porque su salvaguarda es el motivo político eficaz para todos, poseyendo los derechos fundamentales sólo un sentido simbó-

${ }^{14}$ STRECK (2002), p. 104.

${ }^{15}$ Bоввіо (1992), р. 24.

${ }^{16}$ Miranda (1998), p. 177. 
lico en el sentido de aquello que todos creen y quieren; y por último, el realista, según éste, los derechos fundamentales ejercen una función democrática, porque garantizan la libertad y aseguran derechos en el proceso democrático, como también son no-democráticos, pues desconfían del proceso democrático a punto de mantener todas las funciones estatales a vinculadas a ellos, imponiéndoles límites $\mathrm{y}$ restricciones al poder de legislar, ejecutar y garantizar derechos ${ }^{17}$.

Bajo los tres prismas de abordaje, se llega a la premisa de que los derechos fundamentales son esenciales al cumplimiento de los valores democráticos, pues en un Estado en el que no haya respeto a los derechos de igualdad, libertad, pluralismo, soberanía, no habría cómo hablar de un Estado democrático. Así, sus conceptos y fines estarían directamente relacionados y el cumplimiento de ambos resultaría capaz de transformar la sociedad y hacer eficaz la CRFB/1988 (Constitución de la República Federativa de Brasil) en el Estado Democrático de Derecho. Además, se puede decir que la Constitución es el medio y los derechos fundamentales el fin para transformar efectivamente un Estado de derecho en un Estado democrático.

El principio democrático, tal y como lo establece la Ley Fundamental, no actúa sobre la teoría de los derechos fundamentales modificándola o transformándola. La vinculación que el principio democrático y el del Estado de derecho han introducido en el sistema del 'orden fundamental democrático-liberal' radica en que democracia y libertad del Estado de derecho no se anulan parcialmente, sino que se complementan recíprocamente. En el marco de la garantía de la libertad delimitativa del Estado de derecho se hace relevante sin duda el principio democrático. Como principio constitucional fundamental, representa un límite inmanente de la actuación y expansión de la libertad de derecho fundamental. Con ello, se puede prevenir suficientemente los peligros reales que pueden amenazar a la democracia a causa de la expansión del poder y la libertad de los derechos fundamentales ${ }^{18}$.

Sin embargo, la democracia también recibe el status y tratamiento de un derecho fundamental. Aunque los derechos fundamentales de cuarta generación no estén reconocidos unánimemente por la doctrina, importa hablar del entendimiento de parte de la doctrina a continuación relatada sobre el posible reconocimiento de esta nueva dimensión de derechos en el Estado democrático brasileño.

La democracia positivada mientras derecho de cuarta generación tiene que ser, necesariamente, una democracia directa. Materialmente posible gracias a los avances de la tecnologia de comunicación y legitimamente sustentable gracias a la información correcta y a las aperturas pluralistas del sistema. De ese modo, tiene que ser también una democracia

${ }^{17}$ AleXY (1997).

${ }^{18}$ BÖCKENFÖRDE (1993), p. 71. 
exenta ya de las determinaciones de la media manipuladora, ya del hermetismo de exclusión, de indole autocrática y unitarista, familiar a los monopolios del poder. Todo eso, obviamente, si la información y el pluralismo vengan por igual como derechos paralelos y coadyuvantes de la democracia; está, sin embargo, mientras derecho del género humano, proyectado y concretado en el último grado de su evolución conceptual ${ }^{19}$.

Cabe, pues, citar la explicación de Sarlet sobre el pensamiento de Bonavides en lo que se refiere a los derechos fundamentales de cuarta generación:

[...] sosteniendo que esta es el resultado de la globalización de los derechos fundamentales en el sentido de una universalización en el plano institucional, que corresponde, en su opinión, a la última fase de institucionalización del Estado Social. Para el ilustre constitucionalista cearense (brasileño), esta cuarta dimensión está compuesta por los derechos a la democracia (en el caso, democracia directa) es la información, asi como por el derecho al pluralismo. La propuesta del Prof. Paulo Bonavides, comparada con las posiciones que relatan los derechos en contra de la manipulación genética, cambio de sexo, etc., como integrando la cuarta generación, ofrece la nitida ventaja de constituir, de hecho, una nueva fase en el reconocimiento de los derechos fundamentales, cualitativamente diversa de las anteriores, ya que no se cuida solamente de vestir con ropaje nueva reivindicaciones deducidas, en su mayor parte, de los clásicos derechos de libertad ${ }^{20}$.

Los derechos de cuarta generación culminan la objetividad de los derechos de segunda y tercera generación como también los absorben, sin la necesidad de remover la subjetividad de los derechos individuales que componen la primera generación de derechos. Con eso se puede decir que los derechos de segunda, tercera y cuarta generación no se deben interpretar, sino concretizar. Y es justamente en la concretización de esos derechos que habita el futuro de la globalización política (ciudadanía y libertad de todos los pueblos), que actualmente camina sin referencia de valores, silenciosa, pero no por eso deja de dominar a través de las hegemonías supranacionales. Con todo, con la democracia globalizada, el hombre puede avistar la presencia moral de la ciudadanía, la fiscalización de esos derechos será ejercida por el propio ciudadano legitimado por una instancia constitucional suprema, a los modelos de la democracia directa ${ }^{21}$.

Muchas pueden ser las clasificaciones de la democracia en el derecho, tanto en una dimensión individual vinculada con la propia libertad de los individuos y entonces se adentraría a la esfera de los derechos fundamentales de primera

${ }^{19}$ Bonavides (2007), p. 571.

${ }^{20}$ SARLET (2004), p. 59.

${ }^{21}$ Bonavides (2007), pp. 572-537. 
dimensión, así como se podría pensar la democracia considerando un derecho transindividual, referente a la propia solidaridad, adentrándose en la esfera de los llamados derechos de tercera dimensión. Pero lo relevante sobre esta discusión es la importancia de la democracia para la existencia y realización de los derechos de todas las generaciones, eso pues, cuanto mayor sea la voluntad de concretización de estos derechos, es decir, cuanto más perfeccionemos los instrumentos democráticos de participación en las decisiones políticas de las naciones, más cerca estaremos de la sociedad considerada en la esencia de nuestra Constitución.

\section{EL SENTIDO DE LA DEMOCRACIA EN LA SOCIEDAD CONTEMPORÁNEA}

La democracia nació de una concepción individualista de la sociedad, en un momento histórico cuya máxima era la garantía de los derechos de libertad, en contra del arbitrio del Estado, de quien detuviese el poder. Actualmente, el concepto de democracia no se acaba en la protección de los intereses individuales de sus ciudadanos, se puede decir que este concepto ha ganado en el escenario occidental un nuevo concepto, o por lo menos, el antiguo concepto se hizo más amplio, más significativo, más comprometedor.

Una Constitución democrática, como es la brasileña, remite la concretización de los derechos fundamentales y de los principios previstos en el texto constitucional preferentemente a las instancias democráticas del sistema jurídico-político. Exactamente por la legitimidad moral y politica y por el valor epistémico de los órganos y procesos de deliberación democrática, el reconocimiento y la definición del contenido y de la extensión de los derechos fundamentales y de los principios constitucionales en el plano legal compite primordialmente a los órganos de representación de la soberanía popular. (...) Por lo tanto, no son solamente las ideas clave de la separación de los poderes y de la división de competencias que justifican la libertad de conformación legislativa, sino la propia concepción de democracia deliberativa que proviene del principio republicano, como se ha expuesto en los párrafos anteriores. El legislador dispone de libertad para concretar las normas constitucionales, definiendo sus contenidos y estableciendo sus límites, porque es en los parlamentos que deberá ocurrir la plena participación de las personas en los procesos de deliberación pública de las cuestiones politicas de interés de la comunidad, y es por medio de ellos que se extraen normas legitimadas por la ética discursiva y por el valor epistémico que se presuponen atributos de esos procesos. Por eso, el Poder Judiciario de una Constitución republicana deberá adoptar dos especies de posturas respetuosas en relación con los órganos y procesos de representación de la soberanía popular: una postura de deferencia judicial a las decisiones de los órganos de dirección política del Estado; y una postura de garantía y fortalecimiento judicial del régimen democrático ${ }^{22}$.

${ }^{22}$ Mello (2004), p. 178. 
El hecho es que la gama de valores expuestos en el preámbulo constitucional, así como los principios listados en el Art. $1^{\circ}$ de la Constitución de 1988, como siendo los valores fundamentales y de entre ellos la dignidad de la persona humana configurando como una especie de pilar del Estado Democrático de Derecho brasileño, exigen que la democracia amplíe su esfera de actuación, exige compromiso, vincula la esfera de la autonomía individual al compromiso de una dimensión solidaria, más vuelta a la realización colectiva, un verdadero compromiso social.

Una dicha caracterización del Estado social de Derecho significa, no solamente que el principio de la socialidad tiende para el progresivo establecimiento de una democracia económica y social, sino sobre todo y ante nada más, que las esferas de autonomía individual y de los derechos fundamentales -mientras fines y valores esenciales del Estado de Derecho- presupone la existencia efectiva de reglas de la democracia politica, desde la libre elección de una asamblea representativa de todos los ciudadanos y la legitimación democrática de todos los órganos de poder al reconocimiento del pluralismo partidario, derecho de oposición y principio de la alternancia democrática, asi como los derechos de participación politica (nombradamente el sufragio universal y el derecho de asociación), sin cualesquiera discriminaciones de sexo, raza, edad, convicción ideológica o religiosa y condición económica, social y cultural ${ }^{3}$.

En este sentido, el término alcance del principio democrático confiere una nueva lectura a los elementos del Estado de Derecho, comenzándose por la propia división tradicional de poderes, que aunque su existencia esté estrictamente vinculada a la idea de democracia, su rigidez no atiende a las demandas complejas del Estado Democrático de Derecho, que con objeto de la realización de sus objetivos, obliga mayor "interferencia", flexibilización y cooperación en nombre de esta opción de Estado.

[...] asume relieve la concepción, consensualmente reconocida en la doctrina, de que los derechos fundamentales constituyen, para además de su función limitadora de poder (que, además no es común a todos los derechos), criterios de legitimación del poder estatal y, en consecuencia, del propio orden constitucional, en la medida en que el poder se justifica por la realización de los derechos del hombre y que la idea de justicia es indisociable de dichos derechos ${ }^{24}$.

No obstante, se puede afirmar que el Estado Democrático de Derecho está, por así decirlo, impregnado de una intención material, para además de

${ }^{23}$ Novaes (2003), p. 208.

${ }^{24}$ SARLET (2004), p. 69. 
una igualdad ante la ley, que se revela fundamentalmente en la naturaleza de los valores que persiguen una dimensión social de su actividad. Esta intención material de la propia democracia busca la promoción de las condiciones objetivas de desarrollo de la libertad, de la personalidad, que constituyen un momento decisivo en la realización de la justicia social en la sociedad de nuestros días. Estos valores surgen no más en sentido metapositivo, sino en una vinculación axiológica y material implicada en la dignidad humana, así como esta axiología se impone como un límite originario y trascendente al poder del Estado en su conjunto, alejando toda y cualquier reducción formalista de este Estado Democrático $^{25}$.

Pero al pensar en los elementos que involucran el principio democrático expreso por el Constituyente de 1988, encontraremos el siguiente retrato:

10) el elemento democrático, según el que la constitución deberá garantizar que la concretización de los principios y valores en ella instituidos sea realizada por órganos y procesos de deliberación democrática a los que todas las personas de la comunidad puedan tener pleno acceso, y en los que los intereses de todos los individuos sean considerados en un debate público, abierto e irrestricto; $2^{\circ}$ ) el elemento moral sustantivo, por el que la Constitución eleva y asegura algunos bienes y valores sustantivos, materializados en el proceso constituyente en principios y derechos fundamentales por obra de la propia soberania popular, y que son retirados de la libre disposición de los órganos y procesos de dirección politica, porque garantizan la vida digna de la persona humana y la justicia politica de la comunidad; $3^{\circ}$ ) el elemento judicial, que otorga al Poder Judiciario la función de guardián del equilibrio entre el elemento democrático y el elemento moral sustantivo, permitiéndole participar y hasta intervenir en la interpretación y aplicación de las normas constitucionales de los órganos de dirección política de la sociedad, siempre que, de acuerdo con la interpretación del propio poder judicial, ellos frustren el sentido $y$ la finalidad de la Constitución y, con ese error, violen bienes y valores esenciales a la dignidad de la persona humana y a la justicia de la comunidad ${ }^{26}$.

Prima facie, se podría hablar de un concepto de democracia como organización política como de un concepto de democracia entendiéndolo como una sociedad que elige poner en su seno la búsqueda de la igualdad de condiciones. $\mathrm{Y}$ en este sentido, ¿podemos hablar de la democracia que está indisociable de la realización de los derechos fundamentales, así como de la democracia que está indisociable unida al concepto de justicia?, pues ambas compartirían de la misma fragilidad, puesto que también ¿no sería la justicia invocada a proteger

${ }^{25}$ Novaes (2003), p. 212.

${ }^{26}$ Mello (2004), p. 173. 
cualquier atentado en contra de la democracia? De igual modo, ¿el ejercicio de la democracia no se ha invocado para la protección de la justicia social? Cuanto más se emancipa la democracia bajo esta doble forma de organización política y social, más busca ella en la justicia un tipo de salvaguarda, lo que traduce una profunda fortificación en el incremento de propio poder a la justicia en la sociedad contemporánea ${ }^{27}$.

A través de la justicia, la aspiración democrática se confronta con el ámbito social, con las pasiones democráticas, con la acción desmedida de los hombres, con el absurdo de la violencia y los enigmas del mal. Asumir la parte humana de la justicia significa hablar tanto de las pasiones como de la razón, de emociones como de argumentación, de media como de procesos, de prisión como de libertad. Nuestra democracia tal vez tenga menos necesidad de construcciones - o de descontrucciones- teóricas que nuevas referencias para asumir las "mediaciones imperfectas" que son nuestras jurisdicciones ${ }^{28}$.

Como la Constitución brasileña no es una Constitución meramente procedimental-formalista, porque no se resume a instituir órganos y procedimientos democráticos en la democracia participativa o representativa, directa o indirecta, responsables por la determinación de los contenidos jurídicos y a establecer algunos límites materiales a los poderes del Estado. La concepción de Constitución incluye los dichos "mandatos de optimización", es decir, principios como la máxima concretización de valores que derivan de la sociedad asentada por las personas. En otras palabras, pensar en el referido principio democrático exige del intérprete la comprensión de los valores asumidos por la sociedad brasileña y, además, que la soberanía popular encuentra límites y restricciones en nombre de esta dimensión comprometida con el propio concepto de justicia.

\section{CONSIDERACIONES FINALES}

Más que buscar comprender el concepto de democracia en el constitucionalismo contemporáneo, hay que intentar vivenciarlo en el ejercicio diario de la ciudadanía. Ahí está el gran desafío lanzado con la Constitución de 1988: el perfeccionamiento de la democracia y de las instituciones democráticas será capaz de aproximar la sociedad de la verdadera concretización de los derechos fundamentales, de la justicia social.

${ }^{27}$ Garapon (2001), pp. 26-27.

${ }^{28}$ GARAPON (2001), p. 29. 
Se añade al concepto de democracia como forma de gobierno, el concepto de democracia como medio de alcanzar el verdadero sentido de la existencia de una nación, disminuyendo las desigualdades, erradicando la pobreza, respetando la dignidad de cada uno. Pero esta democracia en un plan teórico será siempre una utopía social, pues solamente la concretizamos en la práctica a través de la conciencia ciudadana de que todos somos responsables por una sociedad mejor para las presentes y para las futuras generaciones.

\section{REFERENCIAS}

Alexy, Rober (2002): Teoría de los derechos fundamentales (Trad. de Ernesto Garzón Valdés. Madrid: Centro de Estudios Constitucionales).

Bastos, Celso Ribeiro (2001): Curso de Direito Constitucional (2a ed. São Paulo: Saraiva).

Bobbio, Norberto (1992): A Era dos Direitos (São Paulo: Editora Campus).

BÖCKENFÖRDE, Ernst-Wolgang (1993): Escritos sobre Derechos Fundamentales - Los métodos de la interpretación constitucional (Inventario y critica).

Bonavides, Paulo (2007): Curso de Direito Constitucional (21 a ed. São Paulo: Editora Malheiros).

Canotilho, J.J. Gomes (2003): Direito Constitucional e Teoria da Constituição (3a ed. Coimbra: Editora Livraria Almeida).

CorrêA, Darcísio (2000): A Construção da Cidadania: reflexões histórico-políticas (2a ed. Ijuí: Editora Unijuí).

Garapon, Antoine (2001): O Juiz e a Democracia. O guardiāo das promessas (Trad. Maria Luiza Carvalho. $2^{\text {a }}$ ed. Rio de Janeiro: Renan).

Mello, Cláudio Ari (2004): Democracia Constitucional e Direitos Fundamentais (Porto Alegre: Livraria do Advogado Editora).

Miranda, Jorge (1998): Manual de Direito Constitucional - Tomo IV - Direitos Fundamentais (2a ed. Coimbra: Editora Coimbra).

NOVAES, Jorge Reis (2003): As Restriçōes aos Direitos Fundamentais não expressamente autorizadas pela Constituição (Coimbra: Almeidina).

SARLET, Ingo Wolfgang (2004). A Eficácia dos Direitos Fundamentais (Porto Alegre: Livraria do Advogado).

SiLva, José Afonso da (2000): Curso de Direito Constitucional Positivo (19ª ed. São Paulo: Malheiros).

STRECK, Lênio Luiz (2002): Jurisdição Constitucional e Hermenêutica: uma nova crítica do Direito (Porto Alegre: Livraria do Advogado). 